\title{
Formulatiom, Preparation and Evaluation of Mouth Disintegrating Tablet of Ranitidine $\mathrm{HCl}$ and Domperidone
}

\author{
Suradkar Shivaji Rambhau*, Ambekar Abdul Wahid \\ Department of Pharmaceutics, Dr. V. V. P. F's College of Pharmacy, Vilad Ghat, MIDC, Ahmednagar - 414111, Maharashtra, India.
}

\begin{abstract}
The aim of present study was to prepare the mouth disintegrating combination tablet of ranitidine Hcl and domperidone by using different concentration of superdisintegrants. The tablet were prepared using mannitolas diluent, sodium saccharin as sweetner, potato starch as binder, magnesium stearate as lubricant,avicel as filler or bulking agents along with three different levels of disintegrant. The superdisintegrants use d inthis study are crosprovidone and sodium starch glycolate. The pre-compression evaluation of powder was done such as angle of repose, bulk density, tapped density, carr'scompressibility index and hausner ratio. After compression of tablet post compression evaluation were done like thickness, hardness, weight variation, friability, wetting time, water absorption ratio, disintegration time (DT) and dissolution study. From the obtained results, it can be concluded that the tablet formulation prepared with sodium starch glycolate 50 mg showed disintegrating time of 30 seconds with drug release of $97.17 \pm 1.1,88.82 \pm 0.6 \%$ of ranitidine hydrochloride and domperidone respectively after 30 minute and the hardness, friability, dissolution rate of prepared tablets (batch F3) were found to be acceptable according to standard limits
\end{abstract}

Keywords: Ranitidine Hcl (R-Hcl), Domperidone (DOM), Sodium starch glycolate (SSG), Crossprovidone, Mouth disintegrating tablet (MDT), Direct compression.

Article Info: Received 05 June 2019; $\quad$ Review Completed 24 July 2019; $\quad$ Accepted 02 Aug 2019; Available online 15 August 2019

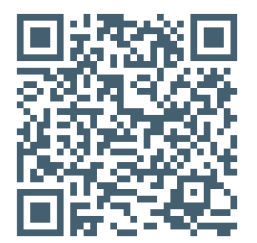

Cite this article as:

Suradkar SR, Ambekar AW, Formulatiom, Preparation and Evaluation of Mouth Disintegrating Tablet of Ranitidine $\mathrm{HCl}$ and Domperidone, Journal of Drug Delivery and Therapeutics. 2019; 9(4-s):497-504

http://dx.doi.org/10.22270/jddt.v9i4-s.3360

Suradkar Shivaji Rambhau, Department of Pharmaceutics, Dr. V.V. P.F's College of Pharmacy, Vilad Ghat PO MIDC; Ahmednagar - 414111 (MS) India.

\section{INTRODUCTION:}

The oral routes of drug administration have wide acceptance that will be up to $50-60 \%$ of total dosage forms. Solid dosage forms are the most popular because of the easy administration, accurate dosage, self-medication, pain avoidance and most important are the patient compliance. US Food and Drug Administration Center for Drug Evaluation and Research (CDER) defines, in the 'Orange Book', an MDT as "a solid dosage form containing medicinal substances, which disintegrates rapidly, usually within a matter of seconds, when placed upon the tongue". The technologies used for manufacturing fast-dissolving tablets are direct compression method, freeze-drying, spray-drying, tablet molding, Sublimation, sugar-based excipients, tablet compression, and disintegration addition 1 .

The formulation was done by using R-Hcl and DOM as an API with different concentration of superdisintegrant such as SSG, Crossprovidone. $\mathrm{R}-\mathrm{Hcl}$ is antacid which used to reduce the gastric acidity. The gastric acidity resulting duo to increasing the $\mathrm{pH}$ level of stomach and duodenum. The gastric acidity occur duo to the excessive secretion of acid in stomach. DOM is antiemetic drug which used to control or to prevent vomiting and nausea. Omitting occurs duo to the stimulations of emetic center such as Chemoreceptor trigger zone (CTZ) ${ }^{2,3}$.

\section{MATERIAL AND METHODS:}

\section{Materials}

R-Hcl and DOM were obtained as gift sample by Ajanta pharma, Aurangabad and Rajesh pharma, Mumbai, india along with their working standard. Sodium starch glycolate (SSG), Crosprovidone, Sodium starch, and Arosil (Ozone international Pvt, Ltd.). Menthol and potao starch from Rajesh pharma, Mumbai, india.All the other chemicals used were of suitable analytical grade.

\section{Methods}

The given amounts of complex equivalent drug was taken and passed through sieve no.80\# and then mixed with directly compressible diluent (mannitol) and superdisintegrants (Crosspovidone, Sodium Starch 
Glyconate) in a mortar. Magnesium stearate, Aerosil, saccharin sodium, were passed through sieve no. 60\#, than crash the menthol into powder than mixed and blended with initial mixture and mix it $10 \mathrm{~min}$ in the mortar followed by compression of the blend using, a single punch multistation compression machine, which is equipped with $12 \mathrm{~mm}$ concave edge punches. The formula is showed in table no.1.

\section{Pre-compression parameter:}

\section{Angle of repose:}

The flow ability of powder was determined by calculating angle of repose by using funnel method. The funnel with 10 $\mathrm{mm}$ internal diameter of stem was fixed at a height of $2 \mathrm{~cm}$ over the platform. About 20 gm of sample was slowly passed along the wall of the funnel till the tip of the pile formed and touches the stem of the funnel. A rough circle was drawn around the pile base and the radius of the powder cone was measured. Angle of repose was calculated from the average radius using the following formula; 4

$$
\theta=\tan -1(h / r)
$$

Where,

$$
\begin{aligned}
& \boldsymbol{\theta}=\text { Angle of repose } \\
& \mathbf{h}=\text { Height of the pile } \\
& \mathbf{r}=\text { Average radius of the powder cone } \\
& \text { Bulk density (Db): }
\end{aligned}
$$

It is the ratio of total mass of powder to the bulk volume of powder. It was measured by pouring the weight powder (passed through sieve \# 20) into a measuring cylinder and initial weight was noted. This initial volume is called the bulk volume. From this the bulk density is calculated according to the formula mentioned below. It is expressed in $\mathrm{gm} / \mathrm{ml}$ and calculated by formula as given 5,6 .

$$
\text { Bulk density }(\mathrm{gm} / \mathrm{ml})=\frac{\text { Weight of sample in } \mathrm{gm}}{\text { Voluwe occupied by sample in } \mathrm{ml}}
$$

\section{Tapped density (Dt):}

It is the ratio of total mass of the powder to the tapped volume of the powder. Volume was measured by tapping the powder for 100 times and the tapped volume was noted. Then, if the difference between these two volumes is less than $2 \%$. If it is more than $2 \%$, then tapping is continued for some times and tapped volume was noted. Tapping was continued until the difference between successive volumes is less than $2 \%$ (in a burette density apparatus). It is expressed in $\mathrm{gm} / \mathrm{ml}$ and given by formula as given 5,6 .

$$
\text { Dt }=\mathbf{M} / \mathbf{V t}
$$

Where, $\mathbf{M}$ - is the weight of sample in grams, Vt- is the volume occupied by the sample.

\section{Compressibility index or Carr's index:}

The simplest method of measurement of flow powder is compressibility, an indication of the ease with which material can be induced to flow is given by compressibility index (I). Compressibility Index is indirect measurement of bulk density, size shape, and surface area, moisture content \& cohesive of material because all of these can influence the observed compressibility index. The compressibility index is calculated as follows ${ }^{7}$.

$$
\text { Compressibility index }=\frac{\text { Tapped density }- \text { Bulk density }}{\text { Tapped density }}
$$

\section{Hausners ratio:}

Hausner ratio is an indirect index of ease of powder flow. It is calculated by the following formula. Lower Hausner's ratio $(<1.25)$ indicates better flow properties than higher ones $(>1.25)^{8}$.

$$
\text { Hausner ration }=\frac{\text { Tapped densty }}{\text { Bulk density }}
$$

Table 1: Formulation table of Mouth Disintegrating Tablets

\begin{tabular}{|c|c|c|c|c|c|c|c|}
\hline \multirow{2}{*}{$\begin{array}{c}\text { Sr. } \\
\text { No. }\end{array}$} & Ingredients & \multicolumn{7}{|c|}{ Quantity in (mg) } \\
\hline & & F1 & F2 & F3 & F4 & F5 & F6 \\
\hline $\mathbf{1 .}$ & Ranitidine Hcl & 150 & 150 & 150 & 150 & 150 & 150 \\
\hline $\mathbf{2 .}$ & Domperidone & 30 & 30 & 30 & 30 & 30 & 30 \\
\hline $\mathbf{3 .}$ & $\begin{array}{c}\text { Sodium Starch } \\
\text { Glyconate }\end{array}$ & 40 & - & 50 & - & 60 & - \\
\hline $\mathbf{4 .}$ & Crosprovidone & - & 60 & - & 60 & - & 60 \\
\hline $\mathbf{5 .}$ & Sodium Saccharin & 30 & 30 & 30 & 30 & 30 & 30 \\
\hline $\mathbf{6 .}$ & Mannitol & 50 & 50 & 40 & 40 & 30 & 30 \\
\hline $\mathbf{7 .}$ & Potato Starch & 15.71 & 15.71 & 15.71 & 15.71 & 15.71 & 15.71 \\
\hline $\mathbf{8 .}$ & Avicel102 & 164.30 & 164.30 & 164.30 & 164.30 & 164.30 & 164.30 \\
\hline $\mathbf{9 .}$ & Aerosil & 10 & 10 & 10 & 10 & 10 & 10 \\
\hline $\mathbf{1 0 .}$ & Menthol & 5 & 5 & 5 & 5 & 5 & 5 \\
\hline $\mathbf{1 1 .}$ & Magnesium stearate & 5 & 5 & 5 & 5 & 5 & 5 \\
\hline \multicolumn{2}{r}{} & & & & & & \multirow{2}{*}{500} \\
\hline
\end{tabular}

\section{Post Compression Parameter:}

\section{General appearance:}

The general appearance is the physical appearance of tablet. It has two aspects, first one is the patient compliance, if the tablet appearance is legible and good. It also help to improve the patient compliance. The second one is for the manufacturer; it helps him in the trouble free manufacturing, if there is tablet to tablet, batch to batch and ISSN: 2250-1177 lot to lot uniformity of tablet.General appearance would include a number of aspects like, size, shape, odor, taste, texture, legibility, and identifying marks 8 .

\section{Thickness:}

The thickness of individual tablets was measured using vernier caliper, which permits the accurate measurements of the thickness and diameter and also provides information of the variation between tablet to tablets. Tablets 
thickness should be controlled within $\pm 5 \%$ variation of a standard value ${ }^{8}$.

\section{Hardness:}

The hardness of six tablets was measured by Monsanto hardness tester. Hardness of tablets was measured in terms of $\mathrm{kg} / \mathrm{cm}^{2} 8$.

\section{Weight variation:}

Weight variation test is accomplished to check that the manufactured tablets have a uniform weight. As per USP, the twenty tablets are weighed separately and an compendia weight is taken, the mean weight is obtained, by dividing the compendia weight by 20 , now the average weight is compared to the individual weight of the tablet, For a tablet to pass the test not more than 2 tablets should lie out of the specified percentage and if no tablet fault by more than two times the percentage limit ${ }^{9}$.

\section{Friability:}

Friability is the test for a tablet to see whether the tablet is stable to abrasion or not, it is tested by using Roche friabilator. This is made up of a plastic drum fixed with a machine which rotated at $25 \mathrm{rpm}$ for 100 revolutions. Then the twenty tablets which were weighed prior to the test are taken out of the drum and cleaned with a cloth and weighed once again, the weight variation must not be less than 0.5 to $1.0 \%$ for a conventional tablet 10,11 .

$$
\text { FriabilityIndex }=\frac{\text { Initial weight }- \text { final weight }}{\text { Intial weight }}
$$

\section{Wetting Time:}

The wetting time of dosage form is related to the contact angle of tablet this method was used to measure tablet wetting time. A piece of tissue paper folded twice, it was placed in a small petri dish of $6.5 \mathrm{~cm}$ in diameter containing $10 \mathrm{ml}$ of $\mathrm{pH} 7.4$ buffer, a tablet was put on the paper, and the time for complete tablet wetting was measured 12 .

\section{Water absorption ratio:}

The water absorption ratios of the tablet were carried out in petri dishes with tablet. it was determined using phosphate buffer $\mathrm{pH}$ 7.4. Periodically, the tablets were withdrawn from the petri dishes and weighed on electronic balance after removal of surface water by light blotting with a lab tissue for change of their weight till a constant weight is attained, tablet was weighed and it was carefully placed on the paper at room temperature (wb). The wetted tablet was reweighed (Wa). Water absorption ratio $\mathrm{R}$, was then determined according to the following equation, 12

$$
R=\frac{W a-W b}{W b}
$$

Where,

Wb and Wa are the weight before and after absorption, respectively.

In vitro disintegration time:

For a drug to be absorbed from a solid dosage form after oral administration, it must first be in solution, and the first important step toward this condition is usually the break-up of the tablet; a process known as disintegration.

The in-vitro disintegration time of a tablet was determined using disintegration test apparatus. It is determined by using disintegration device which consist of 6 glass tubes that are 3 inches long. Open at one end and held against 10 mesh screen at the bottom end of basket rack assembly. To test for disintegration time, one tablet is placed in each tube. All tablets must disintegrate and particles must pass through the 10 mesh in the time specified. In which to prepare the phosphate buffer $\mathrm{pH} 7.4,900 \mathrm{ml}$ was used as disintegration medium, and to maintain the temperature at $37 \pm 0.2^{\circ} \mathrm{C}$. The time was measure in second for complete disintegration of the tablet with there was no palpable mass glass tube 13 .

\section{In vitro Dissolution study:}

Dissolution profiles of R-Hcl \& DOM tablets were determined using the USP Type-II apparatus with paddle speed at 50 rpm. Dissolution was performed in $900 \mathrm{ml} \mathrm{pH} \mathrm{7.4} \mathrm{phosphate}$ buffer solution at $37 \pm 0.5 \mathrm{C}$. $2 \mathrm{ml}$ of samples were withdrawn at $5,10,15,20,25,30$ minutes time intervals. The volume of dissolution fluid was adjusted to $900 \mathrm{ml}$, by replacing each $2 \mathrm{ml}$ aliquot, aliquot were filtered through Whatman filter paper (no.41), further diluted to $10 \mathrm{ml}$ using phosphate buffer pH7.4 solution and analyzed at $314 \mathrm{~nm} \&$ $291 \mathrm{~nm}$ respectively. Using UV-Visible double beam spectrophotometer (JASCO V-630) 12,13.

\section{Drug content:}

An accurately weighed amount of complex (equivalent to 10 $\mathrm{mg}$ of R-Hcl and DOM) was dissolved in small volume of Phosphate buffer PH 7.4 in volumetric flask and made up to the volume .From this solution 5,10, 15, 20, 25,30 ppm concentration are prepared in $10 \mathrm{ml}$ volumetric flask and made up to the volume. The solution was filtered; the absorbance of this solution was measured at $314 \mathrm{~nm}$ and $291 \mathrm{~nm}$ respectively, using appropriate blank.12'13

\section{RESULTS AND DISCUSSION}



Figure 1: UV spectrum of R-Hcl

Table 2: Analytical data for calibration Curve of R-Hcl:

\begin{tabular}{|c|c|}
\hline Concentration & Absorbance at 314nm \\
\hline 2 & $0.1837 \pm 0.04$ \\
\hline 4 & $0.2705 \pm 0.05$ \\
\hline 6 & $0.386 \pm 0.06$ \\
\hline 8 & $0.4998 \pm 0.01$ \\
\hline 10 & $0.5896 \pm 0.02$ \\
\hline 12 & $0.7201 \pm 0.02$ \\
\hline
\end{tabular}

All values are mean \pm SD $(n=3)$ 




Figure 2: Calibration curve of R-Hcl.

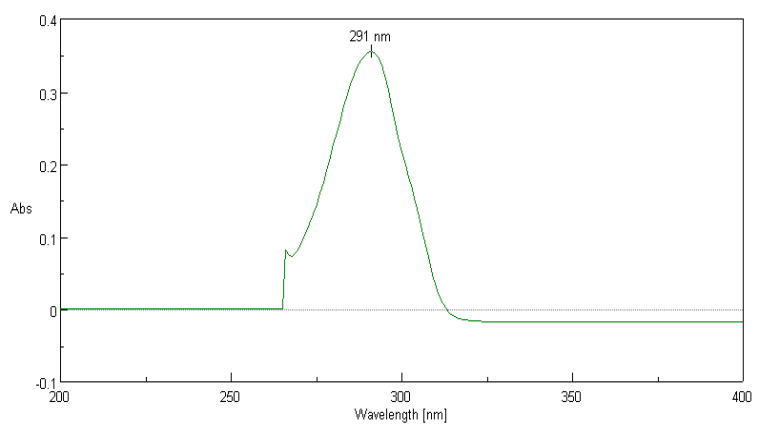

Figure 3: UV spectrum of DOM
Table 3. Analytical data for calibration curve of DOM:

\begin{tabular}{|l|l|}
\hline Concentration & Absorbance at 291nm \\
\hline 2 & $0.079 \pm 0.01$ \\
\hline 4 & $0.187 \pm 0.04$ \\
\hline 6 & $0.289 \pm 0.03$ \\
\hline 8 & $0.422 \pm 0.04$ \\
\hline 10 & $0.554 \pm 0.05$ \\
\hline 12 & $0.672 \pm 0.04$ \\
\hline
\end{tabular}

All values are mean $\pm \operatorname{SD}(n=3)$

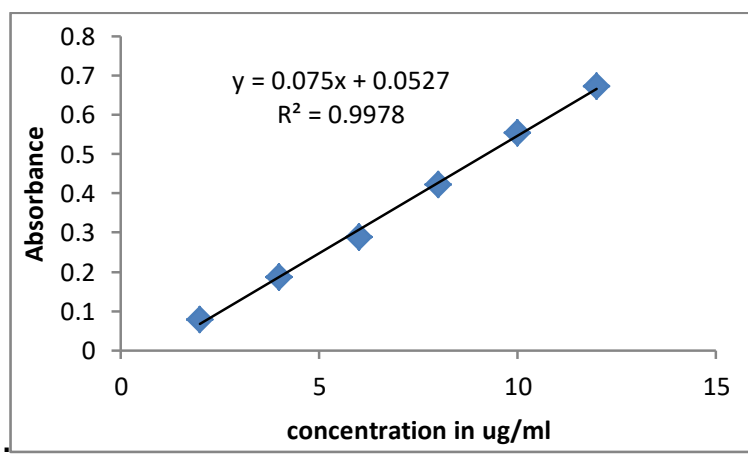

Figure 4: Calibration curve of DOM.

A) R-Hcl:

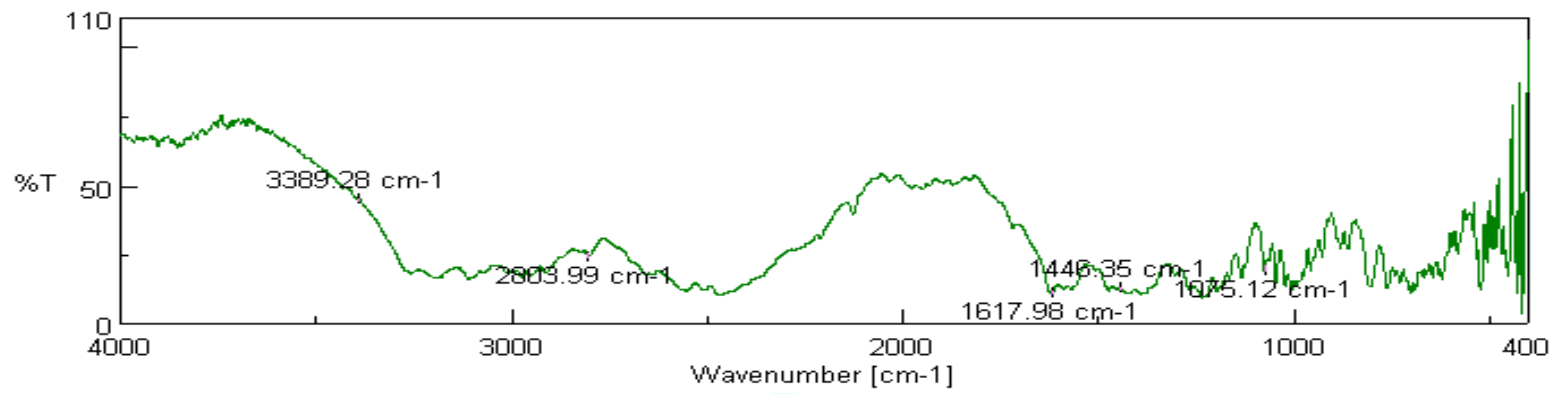

Figure 5: IR Spectrum of R-Hcl.

B) DOM:



Fifure 6: IR spectrum of DOM.

C) R-Hcl + DOM + excipient:

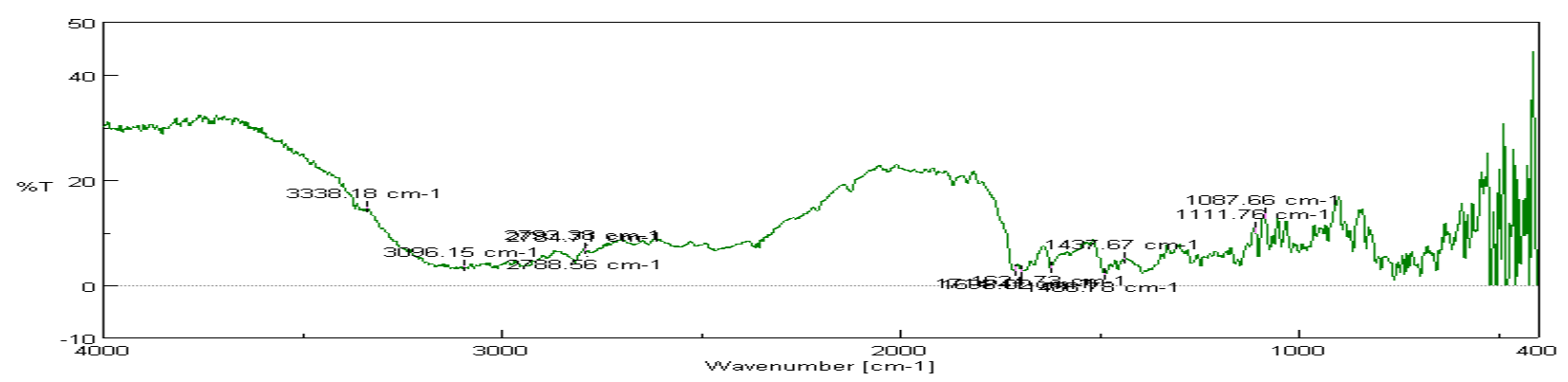

Fifure7: IR spectrum of R-Hcl + DOM + excipient: 
DIYA LABS DSC SI



Figure8: DSC graph of R-Hcl.

DIYA LABS DSC SII

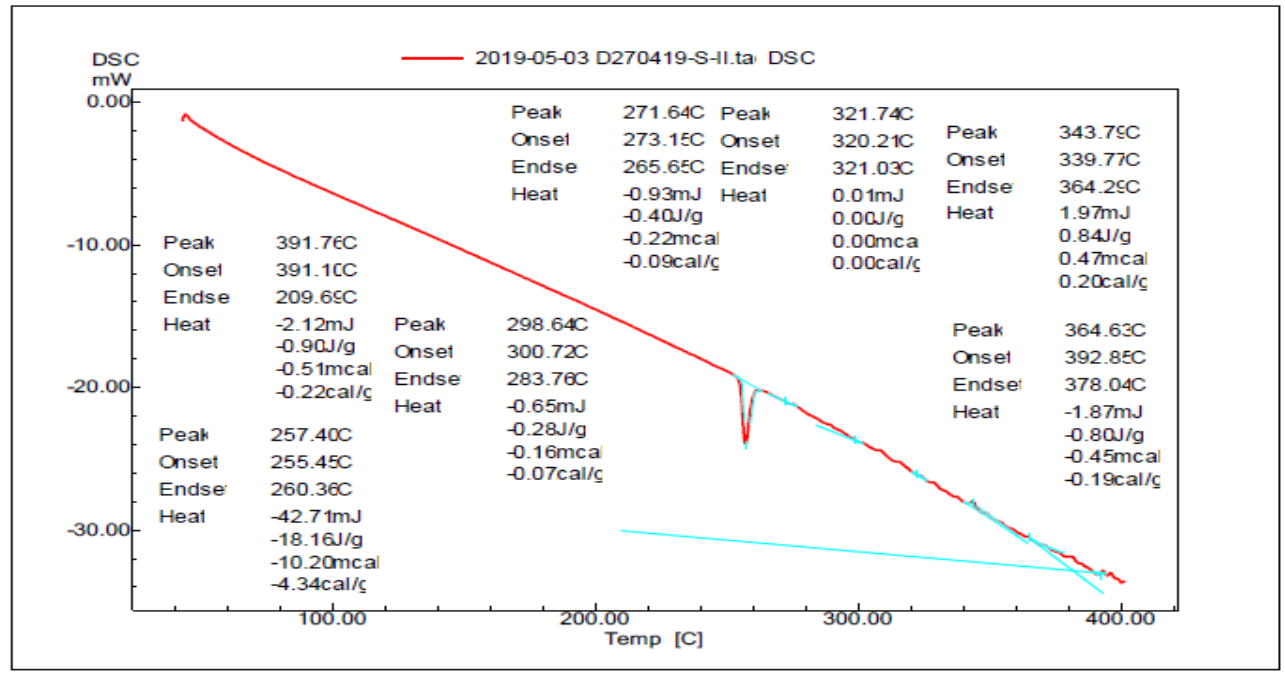

Figure 9: DSC graph of DOM.

DIYA LABS DSC Sample III

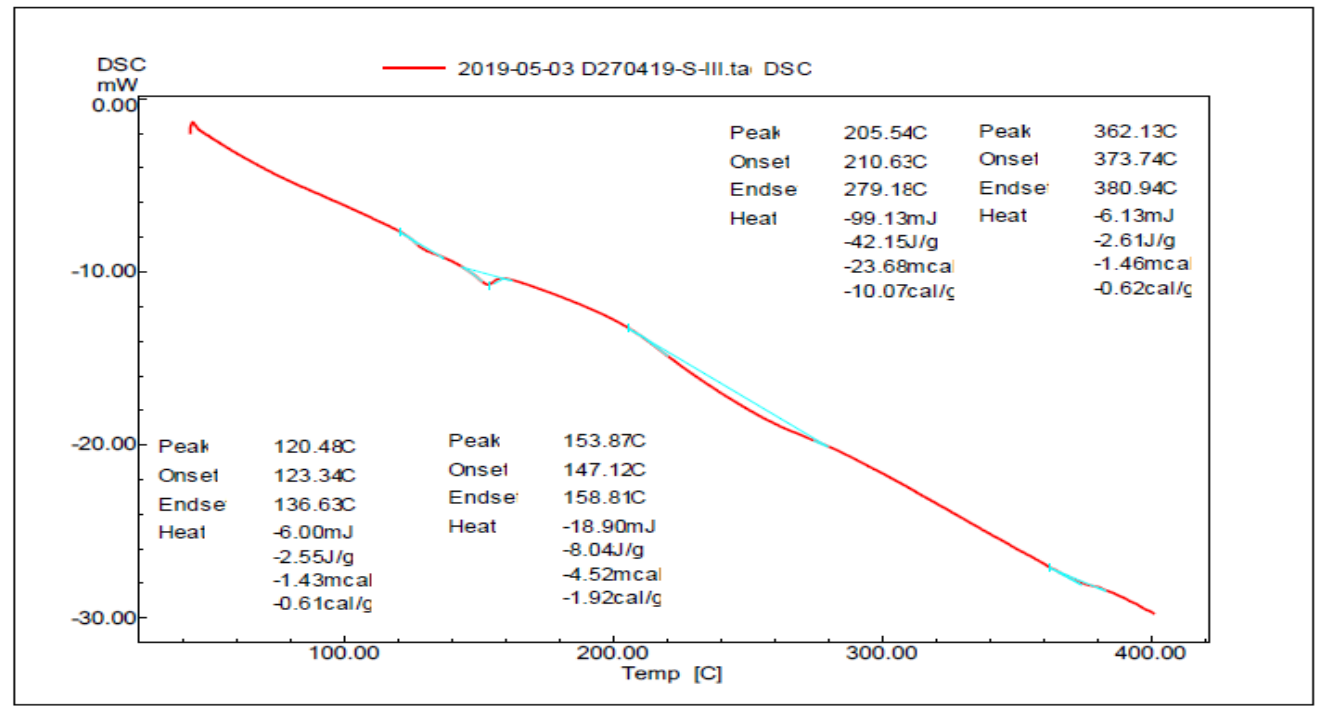

Figure 10: DSC graph Formulation F3. 
Table 4: Characterization of Blends Powder.

\begin{tabular}{|c|c|c|c|c|c|}
\hline Formulations & $\begin{array}{c}\text { Angle of repose } \\
(\theta)\end{array}$ & $\begin{array}{l}\text { Bulk density } \\
(\mathrm{gm} / \mathrm{ml})\end{array}$ & $\begin{array}{c}\text { Tapped density } \\
\text { (gm/ml) }\end{array}$ & $\begin{array}{c}\text { Carr's index } \\
\text { (\%) }\end{array}$ & $\begin{array}{c}\text { Hausner's } \\
\text { ratio }\end{array}$ \\
\hline F1 & $22.78^{0} \pm 0.02$ & $0.49 \pm 0.05$ & $0.58 \pm 0.01$ & $15.51 \pm 0.01$ & $1.18 \pm 0.01$ \\
\hline F2 & $21.80^{0} \pm 0.10$ & $0.51 \pm 0.01$ & $0.57 \pm 0.01$ & $14.03 \pm 0.02$ & $1.16 \pm 0.02$ \\
\hline F3 & $24.56^{0} \pm 0.03$ & $0.58 \pm 0.01$ & $0.66 \pm 0.01$ & $12.00 \pm 0.02$ & $0.87 \pm 0.02$ \\
\hline F4 & $23.740 \pm 0.05$ & $0.47 \pm 0.011$ & $0.55 \pm 0.05$ & $14.50 \pm 0.04$ & $1.17 \pm 0.011$ \\
\hline F5 & $22.29^{0} \pm 0.09$ & $0.56 \pm 0.057$ & $0.67 \pm 0.05$ & $13.98 \pm 0.01$ & $1.18 \pm 0.012$ \\
\hline F6 & $29.80^{0} \pm 0.05$ & $0.48 \pm 0.12$ & $0.56 \pm 0.05$ & $14.28 \pm 0.02$ & $1.16 \pm 0.01$ \\
\hline
\end{tabular}

All values are mean \pm SD $(n=3)$

Table 5: Evaluation of formulated tablets.

\begin{tabular}{|c|c|c|c|c|c|}
\hline $\begin{array}{l}\text { Sr. } \\
\text { No. }\end{array}$ & Formulation & $\begin{array}{l}\text { Hardness } \\
\left(\mathrm{kg} / \mathrm{cm}^{2}\right)\end{array}$ & $\begin{array}{l}\text { Thickness } \\
\text { (mm) }\end{array}$ & $\begin{array}{l}\text { Weight } \\
\text { variation }\end{array}$ & $\begin{array}{l}\text { Friability } \\
\text { (\%) }\end{array}$ \\
\hline 1. & F1 & $3.6 \pm 0.05$ & $2.0 \pm 0.1$ & $0.92 \pm 0.011$ & $0.53 \pm 0.01$ \\
\hline 2. & F2 & $3.5 \pm 0.15$ & $2.1 \pm 0.05$ & $0.74 \pm 0.01$ & $0.79 \pm 0.02$ \\
\hline 3. & F3 & $3.5 \pm 0.15$ & $2.0 \pm 0$ & $1.24 \pm 0.01$ & $0.67 \pm 0.01$ \\
\hline 4. & F4 & $3.9 \pm 0.2$ & $2.2 \pm 01$ & $1.52 \pm 0.02$ & $0.72 \pm 0.011$ \\
\hline 5. & F5 & $3.6 \pm 0.05$ & $2.1 \pm 0.05$ & $1.70 \pm 0.05$ & $0.63 \pm 0.015$ \\
\hline 6. & F6 & $3.7 \pm 0.11$ & $2.1 \pm 0.05$ & $0.97 \pm 0.02$ & $0.68 \pm 0.017$ \\
\hline
\end{tabular}

All values are mean \pm SD $(n=3)$

Table 6: Evaluation of formulated tablets.

\begin{tabular}{|l|l|l|l|l|l|}
\hline $\begin{array}{l}\text { Sr. } \\
\text { no }\end{array}$ & Formulation & $\begin{array}{l}\text { Diameter } \\
\text { (mm) SD }\end{array}$ & $\begin{array}{l}\text { Wetting } \\
\text { Time(sec) }\end{array}$ & $\begin{array}{l}\text { Water } \\
\text { Absorption ratio }\end{array}$ & $\begin{array}{l}\text { Disintegration } \\
\text { Time (sec) }\end{array}$ \\
\hline $\mathbf{1 .}$ & F1 & $12 \pm 0.3$ & $40 \pm 1$ & $28.4 \pm 0.2$ & $35 \pm 2$ \\
\hline $\mathbf{2 .}$ & F2 & $12 \pm 0.4$ & $50 \pm 1.5$ & $36.8 \pm 0.3$ & $50 \pm 2$ \\
\hline $\mathbf{3 .}$ & F3 & $12 \pm 0.2$ & $36 \pm 1$ & $22.0 \pm 0.1$ & $30 \pm 1$ \\
\hline $\mathbf{4 .}$ & F4 & $12 \pm 0.1$ & $55 \pm 0.5$ & $37.4 \pm 0.20$ & $40 \pm 1.34$ \\
\hline $\mathbf{5 .}$ & F5 & $12 \pm 0.3$ & $44 \pm 1.6$ & $24.2 \pm 0.20$ & $35 \pm 0.58$ \\
\hline 6. & F6 & $12 \pm 0.4$ & $61 \pm 2.5$ & $35.6 \pm 0.6$ & $42 \pm 1.50$ \\
\hline
\end{tabular}

All values are mean \pm SD $(n=3)$

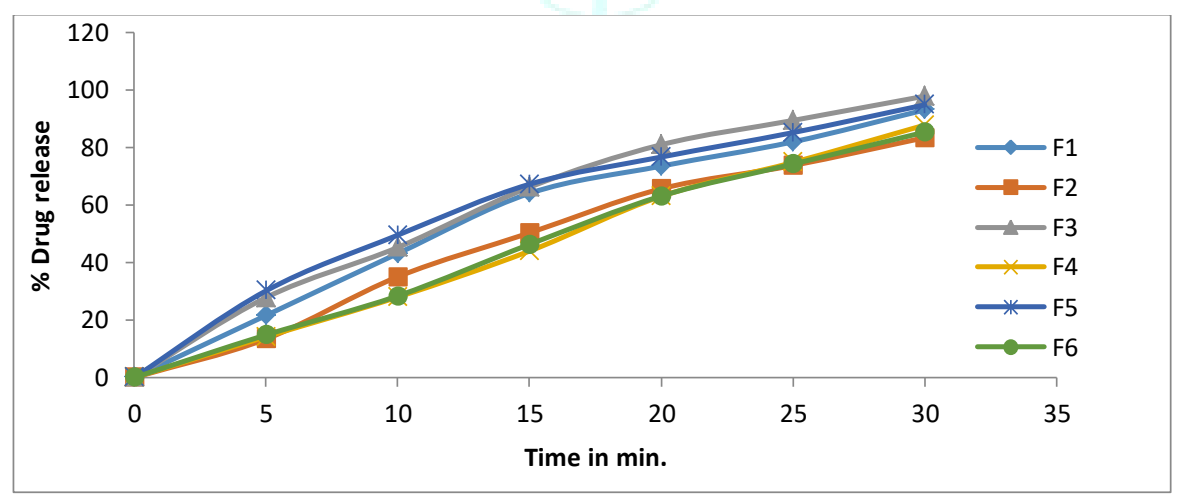

Figure 11:\% Drug release profile of R-Hcl.

Table 7: \% Drug release of R-Hcl.

\begin{tabular}{|l|l|l|l|l|l|l|}
\hline $\begin{array}{l}\text { TIME } \\
(\mathbf{m i n})\end{array}$ & F1 & F2 & F3 & F4 & F5 & F6 \\
\hline $\mathbf{0}$ & 00 & 00 & 00 & 00 & 00 & 00 \\
\hline $\mathbf{5}$ & $21.57 \pm 2.2$ & $13.40 \pm 2.8$ & $27.78 \pm 3.0$ & $14.18 \pm 2.2$ & $34.13 \pm 1.9$ & $14.80 \pm 2.1$ \\
\hline $\mathbf{1 0}$ & $35.96 \pm 3.1$ & $35.00 \pm 2.5$ & $43.23 \pm 2.2$ & $21.96 \pm 2.0$ & $40.50 \pm 2.9$ & $24.37 \pm 2.4$ \\
\hline $\mathbf{1 5}$ & $65.00 \pm 1.9$ & $48.27 \pm 2.3$ & $66.18 \pm 2.1$ & $43.96 \pm 2.4$ & $67.20 \pm 2.0$ & $43.29 \pm 2.5$ \\
\hline $\mathbf{2 0}$ & $72.51 \pm 2.9$ & $65.62 \pm 2.9$ & $80.94 \pm 2.9$ & $63.01 \pm 2.6$ & $72.66 \pm 2.1$ & $63.10 \pm 3.2$ \\
\hline $\mathbf{2 5}$ & $80.93 \pm 2.2$ & $71.72 \pm 3.1$ & $86.38 \pm 2.8$ & $74.78 \pm 2.9$ & $84.16 \pm 2.2$ & $74.22 \pm 2.1$ \\
\hline $\mathbf{3 0}$ & $93.04 \pm 2.1$ & $83.38 \pm 2.2$ & $97.17 \pm 2.1$ & $83.78 \pm 3.2$ & $94.80 \pm 2.5$ & $85.32 \pm 2.2$ \\
\hline
\end{tabular}

All values are mean $\pm \operatorname{SD}(n=3)$ 


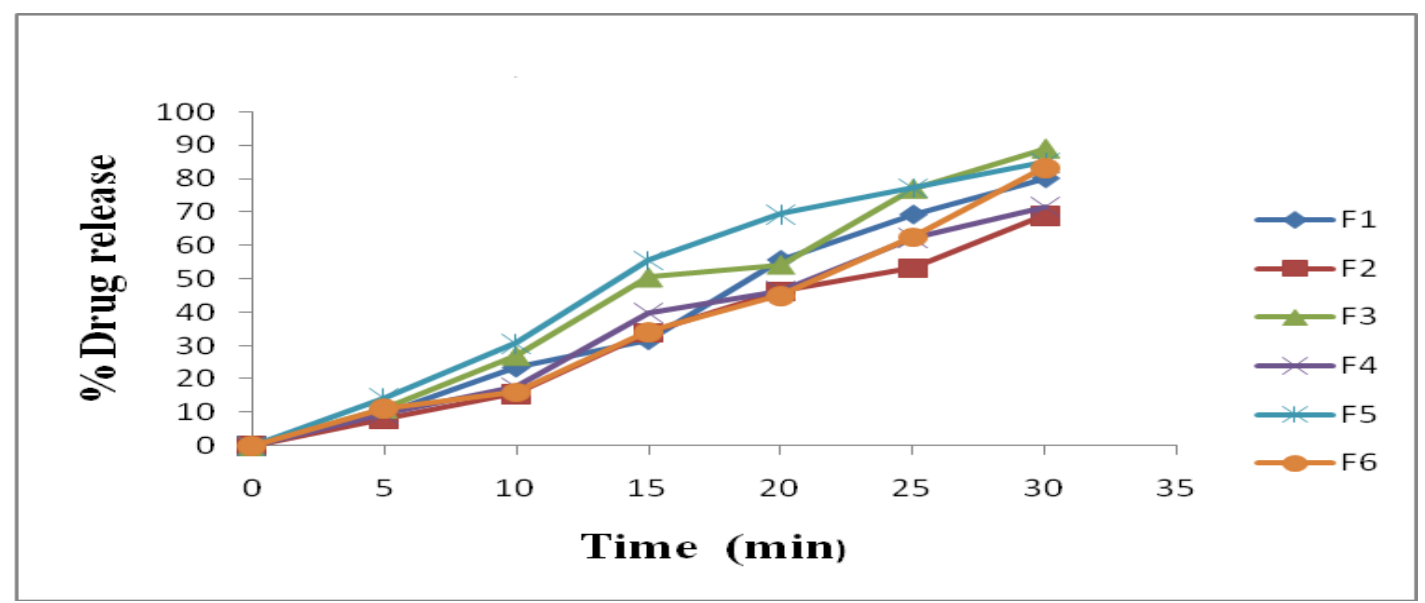

Figure 12: \% Drug release profile of DOM.

Table 8 : \% Drug release of DOM.

\begin{tabular}{|l|l|l|l|l|l|l|}
\hline $\begin{array}{l}\text { Time } \\
(\mathbf{m i n})\end{array}$ & F1 & F2 & F3 & F4 & F5 & F6 \\
\hline $\mathbf{0}$ & 00 & 00 & 00 & 00 & 00 & 00 \\
\hline $\mathbf{5}$ & $09.54 \pm 2.1$ & $08.26 \pm 2.2$ & $11.24 \pm 1.9$ & $09.54 \pm 2.0$ & $14.34 \pm 2.1$ & $11.23 \pm 2.0$ \\
\hline $\mathbf{1 0}$ & $23.5 \pm 2.2$ & $15.67 \pm 2.5$ & $26.96 \pm 2.1$ & $17.70 \pm 2.3$ & $30.68 \pm 2.5$ & $17.96 \pm 2.3$ \\
\hline $\mathbf{1 5}$ & $31.68 \pm 2.3$ & $34.00 \pm 3.1$ & $50.46 \pm 2.2$ & $39.88 \pm 2.6$ & $55.64 \pm 2.3$ & $34.26 \pm 2.6$ \\
\hline $\mathbf{2 0}$ & $55.70 \pm 3.1$ & $46.40 \pm 2.6$ & $64.24 \pm 2.6$ & $46.52 \pm 2.8$ & $69.34 \pm 3.0$ & $45.09 \pm 2.5$ \\
\hline $\mathbf{2 5}$ & $69.24 \pm 2.5$ & $53.12 \pm 3.0$ & $76.98 \pm 2.3$ & $62.32 \pm 1.6$ & $77.22 \pm 2.6$ & $62.62 \pm 2.4$ \\
\hline $\mathbf{3 0}$ & $80.04 \pm 2.9$ & $69.08 \pm 2.1$ & $88.92 \pm 3.6$ & $77.54 \pm 2.2$ & $84.90 \pm 3.1$ & $83.42 \pm 2.9$ \\
\hline
\end{tabular}

Table 9: \% Drug release and \% drug content

\begin{tabular}{|l|l|l|l|l|l|}
\hline \multirow{2}{*}{$\begin{array}{l}\text { Sr. } \\
\text { No. }\end{array}$} & Formulation & \% Drug Release & \% Drug content \\
\cline { 3 - 6 } & & R-Hcl. & DOM & R-Hcl. & DOM \\
\hline 1. & F1 & $93.04 \pm 2.1$ & $80.04 \pm 2.9$ & $98.92 \pm 3.0$ & $93.99 \pm 2.2$ \\
\hline 2. & F2 & $83.38 \pm 3.2$ & $69.08 \pm 2.1$ & $97.98 \pm 2.9$ & $93.56 \pm 2.1$ \\
\hline 3. & F3 & $97.17 \pm 2.4$ & $88.82 \pm 3.6$ & $99.90 \pm 2.9$ & $97.89 \pm 3.1$ \\
\hline $\mathbf{4 .}$ & F4 & $83.78 \pm 3.2$ & $77.54 \pm 2.2$ & $99.87 \pm 3.2$ & $94.52 \pm 2.6$ \\
\hline $\mathbf{5 .}$ & F5 & $94.80 \pm 2.5$ & $84.90 \pm 3.1$ & $98.91 \pm 3.1$ & $95.91 \pm 3.1$ \\
\hline 6. & F6 & $85.32 \pm 4.0$ & $83.42 \pm 2.9$ & $99.05 \pm 3.2$ & $94.97 \pm 1.2$ \\
\hline
\end{tabular}

All values are mean \pm SD $(n=3)$

\section{DISCUSSION:}

In the present study first compatibility studies with various excipients and API was found to be compatible with all the excipients, study was done by FTIR and DSC.Then various Pre-compression parameters like bulk density, tapped density, Hausner's ratio, Carr's consolidation index and angle of repose were determined and found to be within the limits and post compression parameters like hardness, thickness, weight variation, friability, wetting time, water absorption ratio were determined and found to be within range. The disintegration time of all the formulation is 30-50 second and In-vitro dissolution of all the formulations were analyzed and among all the six formulations, F3 shown maximum drug release of $97.17 \pm 2.4, \quad 88.82 \pm 3.6 \%$ of ranitidine hydrochloride and domperidone respectively after 30 minute.

\section{CONCLUSION:}

Fast dissolving drug delivery will be used widely in the coming years to impart better patient compliance. Since mouth disintegrating tablet is useful in enhancing drug disintegration and dissolution within seconds, it becomes popular. In addition, they will become a solution for patients who have difficulty swallowing and need rapid onset of action. In this study formulation of mouth disintegrating tablet using ranitidine hydrochloride, domperidone as API with using sodium starch glycolate and crossprovidone as superdisintegrant. Formulation F3 is optimized formulations, it show good precompression and postcompression parameter. It shows good hardness, friability and disintegrating time, drug content and dissolution study. It disintegrates within 30 second with $97.17 \pm 2.4 \%$ and $88.82 \pm 3.6 \%$ drug release of R-Hcl and DOM respectively.

Thus it can be concluded that mouth disintegrating tablet of R-Hcl and DOM can be prepared using SSG (sodium starch glycolate) as superdisintegrating agent which can be used in emergency with no need of water.

\section{ACKNOWLEDGEMENT}

The authors are thankful to the principal and management of Dr. Vithalrao Vikhe Patil Foundation College of Pharmacy, Ahmednagar for providing necessary facilities to carry out this work.

\section{REFERENCES:}

1. Singh SK, Mishra D, A Research on Fast Disintegrating Combination Tablet of Omeprazole and Domperidone, Asian Journal of Pharmaceutical and Chemical Research, 2009; 2(3): 74-82.

2. Shah Nihar, Patel Nitish, A Research on Formulation and Development of Fast Disintegrating Tablet using Ranitidine $\mathrm{Hcl}$ as a model drug, Journal of Pharmaceutical Science and Bioscientific Research, 2011;1(1): 65-70. 
3. Haseena Ayesha, KauserAsfia , Taiyaba Fatima, Majeed Zaara And Mohammed Farhana, Formulation and Evaluation of Oral Disintegrating Tablets of Domperidone, World Journal of Pharmacy And Pharmaceutical Sciences, 2018; 7(3): 615-640.

4. Jain Piyush, Gupta RN, Shrivastava Sandeep, A Research on Formulation and Evaluation of Mouth Dissolving Tablets of Omeprazole, International Journal of Current Pharmaceutical Research, 2016; 8(2): 48-51.

5. Das Pravita , Pandya Susmita, Formulation Development and Evaluation of Ranitidine Hcl Tablet, Eropean Journal of Biomedical and Pharmaceutical science, 2017; 4(12): 885-896.

6. Sarangi DK, Patra Niranjan, a research on Development of Mouth Dissolving tablet ranitidine hcl $150 \mathrm{mg}$, Journal of Pharmaceutical Sience and Technology Development, 2015; 3(4): 586-591.

7. Rabadiya Bhavisha, Research on Drug-Excipient Interaction and Test Masking Tablet of Ranitidinine Hcl, IJPRBS, 2013; 2(1): 168-185.

8. AggerwalGeeta, Heer Deepak and Kumar Hari, Recent trends of fast dissolving drug delivery system an review of formulation technology, Journal of Pharmacophore,2013; 4(4): 1-9.

9. Prajapati B, Ratankar N, Fast Dissolving Drug Delivery System" International journal of Pharma Tech and Research,
2011;1(3): 790-798.

10. Mahantesh MK, A Research on Formulation and Evaluation of Metoclopramide Mouth Dissolving Tablet, International Journal of Pharmacy and Pharmaceutical Sciences, 2011; 5(2): 56-62.

11. Gadad AP, Dandagi PM, Patil MB, Non-Chewable Antacid Formulation: Effect of Different Agents on their Acid Neutralization Properties, Indian journal of pharmaceutical sciences, 2009; 5(2): 269271.

12. Sharma Sachin, Kumar Jitendra, Arya Arun and Chandra Amrish, A Research on Formulation and Evaluation of Mouth Dissolving Tablets of Ranitidine Hcl" International journal of Pharma Tech, 2010; 5(4) : 1574-1577.

13. Shrinu Ravi, Design and Development of Fast Dissolving Tablets Simvastatin using Novel co- processed Superdisintegrants, Journal of Drug Delivery Research, 2013; 2(1): 27-52.

14. Ansari Muhammad Iqbali, Kamran Zaheer and Kamran Ahmad, A Research on Development and Evaluation of Orally Disintegrating Tablets of Montelukast Sodium by Direct Compression Method, Topical Journal of Pharmaceutical Research, 2015;14(01): 1-6.

15. Gauri Samita, Fast Dissolving Drug Delivery and its Technologies, The Pharma Innovation, 2012; 1(3): 34-39. 